\title{
The Asian Tapir in Kerinci Seblat National Park, Sumatra: evidence collected through photo-trapping
}

\author{
Jeremy Holden, Achmad Yanuar and Deborah J. Martyr
}

\begin{abstract}
Kerinci Seblat National Park (KSNP) is the largest protected area in which Asian tapir Tapirus indicus occurs. Data collected during 3 years of biodiversity surveys indicated that KSNP is one of the most important remaining areas for Asian tapir. Evidence of tapirs was collected by photo-trapping, recording of tapir signs, and interviewing local people. Photo-trapping was carried out in four locations, each representing a different forest type. The results showed that the Asian tapir is widespread throughout the Park and found in a variety of habitats, from montane cloud forests to the degraded fragments of remaining lowland forest. Although formerly believed to be solitary, tapirs were
\end{abstract}

often photo-trapped in pairs. Repeat 'recapture' of the same individuals suggests that these pairings may be of long duration. Evidence of distribution and threats throughout the Park and adjacent forests was collected to produce a greater understanding of how best to safeguard the future of this species in KSNP. Deliberate hunting of tapirs in KSNP was found to be rare, and habitat loss and fragmentation poses the most serious threat.

Keywords Asian tapir, forest fragmentation, Kerinci Seblat National Park, photo-trapping, Sumatra, Tapirus indicus.

\section{Introduction}

The Tapiridae contains four species, three of which are found in Central and South America, with the Asian (or Malayan) tapir Tapirus indicus being the only Old World species. Fossil evidence indicates that Asian tapir ranged as far east as Borneo during prehistoric times (Medway, 1961). Historically the range extended through Burma and Thailand to Cambodia and Viet Nam, but much of the former range is now highly fragmented (Khan, 1997). The species' present range is restricted to South-east Asia, with scattered populations in Thailand, Burma (south of latitude $18^{\circ} \mathrm{N}$; Lekagul \& McNeely, 1977), Peninsular Malaysia, and Sumatra.

Asian tapir are categorized as Endangered on the 2002 IUCN Red List (IUCN, 2002), and have been protected in Indonesia since 1931. In Sumatra the species is found in at least seven of eight provinces. Although it is absent from Aceh and most of North Sumatra province, it is present throughout the area south of Lake Toba (Meijaard, 1999). Populations are found in both Way Kambas National Park at Sumatra's southern tip (N. Franklin, pers. comm.), in the Bukit Barisan Selatan National Park along the south-west coast (O'Brien \&

Jeremy Holden (Corresponding author) Achmad Yanuar and Deborah Martyr Fauna \& Flora International, PO Box 42, Sungai Penuh, Jambi, Sumatra, Indonesia. E-mail: POP@padang.wasantara.net.id

Received 6 September 2001. Revision requested 27 February 2002 Accepted 29 August 2002
Kinnaird, 1996), and in Kerinci Seblat National Park (KSNP), with the highest populations in Jambi province (Blouch, 1984). Locally tapir are known as tenuk, but in rural areas around KSNP they can be called cipan, tanuak or kampuah tangah duo. A Kerincinese rural legend that describes a type of forest horse known as kuda aras probably refers to tapir.

The New World tapirs are comparatively better studied than the Asian tapir (Fragoso, 1991; Downer, 1996; Salas, 1996; Medici \& Padua, 1999), perhaps because they are the largest mammals occurring in the region. The Asian tapir, however, is poorly known, with data lacking for the species across its range. KSNP offers considerable potential for the of study Asian tapir because it has the largest area of continuous forest in which they are found.

In this paper we demonstrate that photo-trapping is a useful method for study of the Asian tapir. We provide information on tapir ecology, obtained through phototrapping, and discuss how this relates to the conservation of this species in KSNP.

\section{Methods and study area}

The forested area encompassing the volcanoes of Kerinci and Seblat was officially designated as a National Park in 1986. The protected area covers $c .13,300 \mathrm{~km}^{2}$ in westcentral Sumatra, across the provinces of Jambi, West Sumatra, Bengkulu and South Sumatra, and straddles the spine of the Barisan mountain range that lies along western Sumatra (Fig. 1). Altitudes range from 200 to 


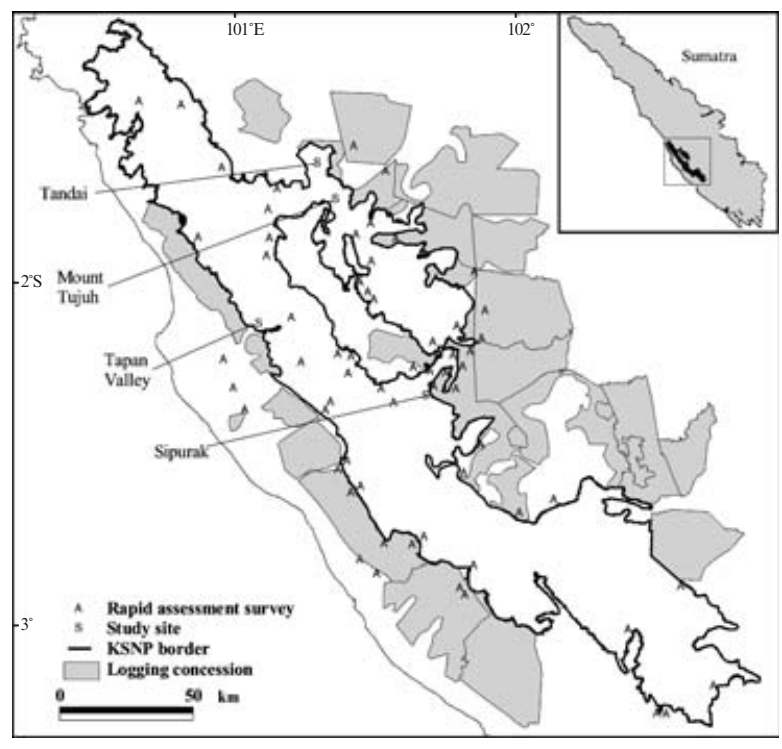

Fig. 1 Kerinci Seblat National Park (KSNP) and adjacent logging concession areas, and the locations of the four study areas and the sites where rapid assessment surveys were carried out. The inset map indicates the position of KSNP in Sumatra.

3,805 m, the highest point in Sumatra (Mount Kerinci). Forest type is predominantly hill dipterocarp forest covering steep valleys and narrow ridges, but habitat types include some lowland forest in the west, high altitude peat swamp, montane cloud forest, and alpine scrub on the highest areas. Despite its large area, the shape of KSNP, with $2,500 \mathrm{~km}$ of border, makes it highly susceptible to fragmentation. The fauna includes Asian elephant Elephas maximus, Sumatran rhinoceros Dicerorhinus sumatrensis, serow Naemorhedus sumatrensis, bearded pig Sus barbatus, tiger Panthera tigris sumatrae, clouded leopard Neofelis nebulosa, the endemic Sumatran hare Nesolagus netscheri, and eight primate species (Martyr, 1997). Three hundred and seventy bird species have so far been recorded (Holden, 2002). Plant diversity in and around KSNP is extremely high (Gillison et al., 1996), including Rafflesia hasselti and the huge aroid Amorphophallus titanum.

During this study, from 1996 to 1999, photo-traps were set in four areas (Fig. 1), each of which represented a different type of habitat or altitudinal zone characteristic of KSNP.

Tapan Valley, West Sumatra province, consisted of remnant primary and disturbed lowland hill forest at $125-400 \mathrm{~m}$. The study area was both inside the park borders and in adjacent buffer zone forest. Both old and new ladang (farmland created by clearing forest) plus various mining and logging operations had disturbed the forest. Elephant and rhinoceros, the animals closet in size and ecology to tapirs, were extirpated in the area many years previously. An asphalt road between Tapan and Sungai Penuh bisected the study area. Photo-traps were operated between November 1996 and May 1997 for a total of 31,000 trapping hours.

Tandai, West Sumatra province, was a mosaic of secondary logged forest grading into primary forest above $900 \mathrm{~m}$. Surveys were at 500-900 m. This area was responsibly logged seven years previously, but smallscale illegal logging activity continued up until the beginning of the study period. The core study area was in heavily logged forest with a seriously damaged canopy and a network of open dirt roads. Elephants and rhinoceros were extirpated in this area. Photo-traps were operated between April and September 1996 for a total of 50,000 trapping hours, along old logging roads and forest trails.

Sipurak, Jambi province, is an area of primary forest at altitudes at 600-1,000 $\mathrm{m}$ with little human disturbance. The core study area was undulating hill forest between river valleys with a number of salt licks formed by the thermal activity of two volcanoes. With the exception of Sumatran rhinoceros, which was not recorded within the study area but is reportedly present in adjacent areas, the mega fauna was intact, with elephant and large cervid populations. Photo-traps were operated during September and October 1998, and between May and October 1999, totaling 28,000 trapping hours, along open ridge and riverine trails, and beside salt licks.

Mount Tujuh, Jambi province consisted of primary forest over altitudes of 1,800-2,400 m, characterized by extremely steep terrain rising from the shores of a volcanic crater lake. The forest type is hill Dipterocarp and submontane, with montane cloud forest on the highest peaks. The vegetation is undisturbed but the fauna is impoverished due to excessive trapping with snares. Rhinoceros has been extirpated and cervids and serow are rare. Photo-traps were operated between May and October 1997 for a total of 23,000 trapping hours, along ridge trails between peaks or along the edge of the lake.

Data on tapirs collected during this study formed part of wider biodiversity surveys (predominantly for large mammals and birds). Areas chosen for surveys were initially identified from maps and through interviews with the local community. Short rapid assessment surveys (Fig. 1) were then made to assess conditions, during which any signs of tapir were noted. In suitable areas an intensive study over 6 or more months was conducted and photo-traps set. Where possible local guides were used who knew the area and could provide reliable information.

Signs left by tapirs include dung, sleeping areas, trampled saplings (knocked down during feeding), shed hairs where they had rubbed themselves against tree 
trunks, and footmarks. Footmarks are distinctive and easily found because tapirs have four toes on the front feet and three on the back, prints of which can only be confused in Sumatra with those of Sumatran rhinoceros. The rear foot often overprints the fore foot to produce an unmistakable five-toed print that looks like a gloved hand. Dung was also unmistakable, formed of mounds of small plum-sized pellets.

Trail Master ${ }^{\mathrm{TM}}$ 1,500 trail monitors were used for phototrapping. These consist of a transmitter unit, receiver, and compact Olympus Infinity camera with built in flash and $38 \mathrm{~mm}$ auto-focus lens. Passing animals are detected and the camera shutter is triggered when the infrared beam, which can be set to varying sensitivities, is broken.

Proposed photo-trapping areas were firstly surveyed to define where animals were moving, and placement locations were chosen to maximize capture rate. Existing animal trails were chosen and placements made at sites where natural channeling of animal movements may occur. Placements were of two sorts: active and passive. Passive placements were those made along animal trails, recording only those animals that were passing. Active placements involved the placing of baits or otherwise staking out a food source such as a fruiting trees of durian Durio spp. and jackfruit Artocarpus spp. In these instances additional bait was supplemented, or fallen fruit moved in front of the camera. Each time the infrared beam was broken by a passing animal, an 'event', the date and time were recorded automatically by both the camera and the monitor, allowing animal movement times to be documented. The term 'occasion' is used here for each time that an animal, or pair of animals, passed through the placement, irrespective of how many 'events' occurred. For each study site encounter rates were calculated by dividing the number of trap days by the number of 'occasions' that tapirs were photographed. Between five and 19 photo-traps were employed at any one time.

Identifying individuals was difficult because tapirs have few distinguishing characteristics. Three methods were used: distinctive scarring, damage to ears, and

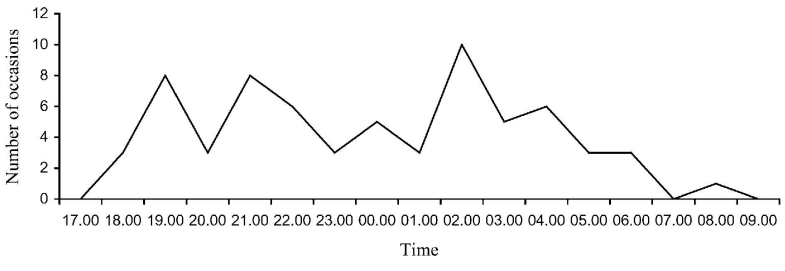

Fig. 2 For all camera placements combined over the study period, the number of 'occasions' (see text for further details) on which photographs were made by the photo-traps (see Table 1) between 17.00 and 09.00 . No photographs were made at other times.

irregularities along the borders of the white saddle mark, particularly on the front flanks and stomach. Damage to ears was the most useful because the ears are prominent and almost always visible in photographs. Scarring was useful only with deep and permanent scars because tapirs receive many superficial scars that in repeat photographs were seen to quickly heal. Tapirs were classed as moving as a pair if they were photographed either together in the frame or at the same placement within an hour of each other. Some of the paired photographs showed adults with subadult calves. In these instances the hide was examined for scars and unscarred individuals were categorized as subadults. Animals were categorized as subadults if there was otherwise any doubt.

\section{Results}

The presence of tapirs was confirmed in all areas of the park and its adjacent forests that were surveyed (Fig. 1). Tapirs were found at all altitudes in all habitats surveyed, but encounter rates were generally greater at lower altitudes (Table 1). Records were obtained from both altitudinal extremes represented by the survey areas, in swamp forest adjacent to the park in West Sumatra province at $50 \mathrm{~m}$ and in cloud forest at Gunung Tujuh at 2,400 m, where tapirs were regularly moving and feeding along ridge trails. In disturbed and old logged forest tapirs frequently moved along human trails and logging roads.

Table 1 Photo-trapping results from the four survey locations (see Fig. 1)

\begin{tabular}{|c|c|c|c|c|c|c|c|c|}
\hline Location & $\begin{array}{l}\text { Altitude } \\
(\mathrm{m})\end{array}$ & $\begin{array}{l}\text { Area } \\
\left(\mathrm{km}^{2}\right)\end{array}$ & $\begin{array}{l}\text { Habitat } \\
\text { Type }\end{array}$ & $\begin{array}{l}\text { Trapping } \\
\text { Hours }\end{array}$ & $\begin{array}{l}\text { No. camera } \\
\text { placements }\end{array}$ & Occasions* & $\begin{array}{l}\text { Number of } \\
\text { tapir }\end{array}$ & $\begin{array}{l}\text { Encounter rate } \\
\text { (days per tapir photo) }\end{array}$ \\
\hline Tapan Valley & $125-400$ & 8 & Disturbed & 31,000 & 31 & 25 & 15 & 51.7 \\
\hline Tandai & $500-900$ & 12 & Secondary & 50,000 & 26 & 30 & 8 & 69.4 \\
\hline Sipurak & $600-1,000$ & 8 & Primary & 28,000 & 14 & 19 & 5 & 61.4 \\
\hline Mt Tujuh & $1,800-2,400$ & 5 & Primary & 23,000 & 13 & 4 & 1 & 239.5 \\
\hline
\end{tabular}

*Number of times that a tapir, or pair of tapirs, passed through the camera placement, irrespective of how many photographs were made. 


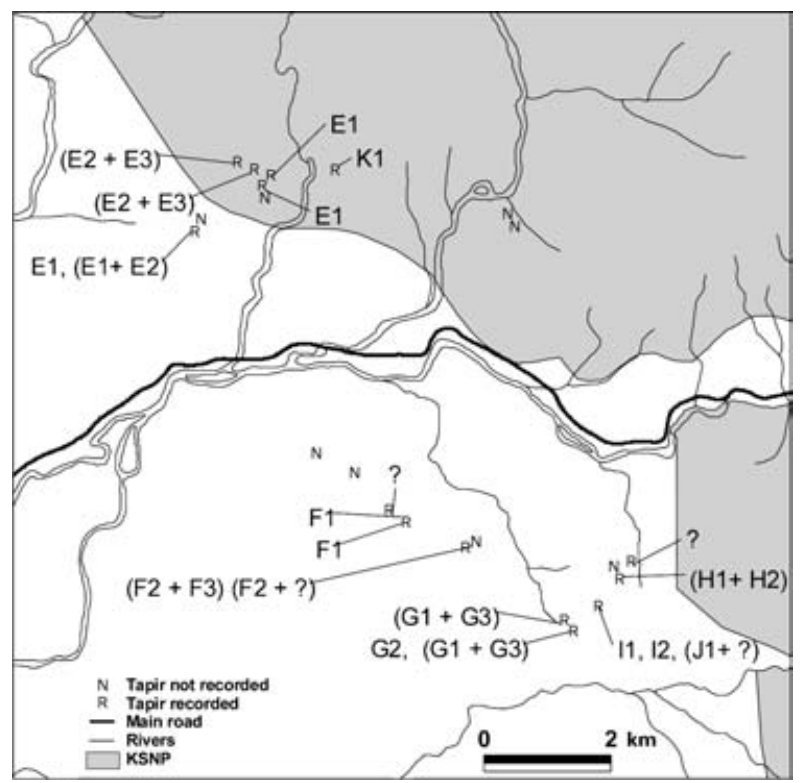

Fig. 3 Distribution of camera placements in Tapan Valley showing tapirs photographed individually and in pairs (the latter in parentheses). Letters and numbers refer to individual tapirs, where identified, and '?' to unidentified individuals.

Between April 1996 and October 1999 photo-traps were operated for a total of 132,000 hours. Throughout the four locations a total of 84 camera placements were made, 35 of which made photographs of tapirs. Tapirs passed through photo-traps on 78 occasions, and a total of 227 images were made. Careful scrutiny of all images allowed identification of 29 individual tapirs with certainty, with a possible five more that could not be conclusively identified (Table 1). Usually tapirs passed the photo-traps without pause, although on one occasion tapir tracks were followed that faltered before a placement, suggesting the animal had shied away from passing the camera. On one occasion one of the units was attacked and disabled by a tapir.

Compilation of all the recorded times that tapirs passed through camera placements demonstrated that the species is unequivocally nocturnal, and active throughout the night, with no evidence of crepuscular activity (Fig. 3). Animals were most often photographed moving along forest trails, but photographs were also made of animals walking along open logging roads in Tandai, drinking at salt licks in Sipurak, and eating fallen jackfruit in Tapan Valley. Tapirs were photographed in pairs on $20 \%$ of occasions, $14 \%$ of which showed two adult animals and $6 \%$ an adult and a calf. The only sighting of a tapir during the study was by a local assistant who saw a pair fording a river during daylight hours.

\section{Discussion}

This study has demonstrated that photo-trapping is a successful method for gathering evidence of what was previously thought to be a difficult animal to study. Tapirs are extremely elusive, and it is indicative of their shyness and ability to avoid contact with humans that in thousands of hours of fieldwork in KSNP none of the survey team, and only one guide, ever saw a tapir. Even amongst local people they are little known and when we produced the first photo-trap pictures many of the Park rangers were not familiar with the animal and asked what it was. Our results showed that tapirs are widespread throughout the Park, almost exclusively nocturnal, and often move in pairs.

Tapirs did not utilize only primary forest. They were photo-trapped in both old and recently logged forest, old rubber plantations, disturbed forest edge, and in one case footprints were found that crossed an open cultivated area. The situation in KSNP contrasts to that reported for Peninsular Malaysia where tapirs are considered predominantly animals of the primary forest (Williams, 1980). However, although tapirs are using previously logged forest for browsing, it is likely that they require nearby areas of primary forest as refugia (Santiapillai \& Ramono, 1990).

In comparison with other species that were regularly photo-trapped during the study only porcupine Hystrix brachyura was more nocturnal, never being photographed during daylight hours. Tapirs were photographed during full daylight on only two occasions, and on a further three during dusk and dawn. Daylight or crepuscular photographs were made in all four of the study areas, regardless of human disturbance. This indicates that tapirs have not changed their activity periods to avoid contact with humans, as is the case with other rain forest mammals such as Malay sun bear Helarctos malayanus (Griffiths, 1993).

Tapirs had the highest incidence of pairing of all of the large mammals photo-trapped. Tigers were never photographed together, and Malay sun bears only once. Asian tapirs have usually been described as solitary (Santiapillai \& Ramono, 1990) and as sometimes moving in pairs (Williams, 1980; Lynam, 1999). It is difficult to determine from footmarks alone if animals are moving together. Because of their browsing habits tapirs spend most time wandering in the forest and moving in a haphazard fashion (Lekagul \& McNeely, 1977), making it easy to confuse footprints of different individuals. Even when it is clear that two animals have been moving together it is not always possible to determine if the second animal is another adult or a subadult or calf. Photo-trapping allowed us to determine this. It is possible that tapirs were with a companion on more 
occasions than the photographs showed, as even when animals were photographed in the same frame some pictures showed one of the pair moving through the forest off the path (Plate 1). At one placement in Tandai, where animals have to move along a narrow ridge, tapirs were only ever photographed in pairs, three times over a period of 3 months. On all three occasions the same pair were photographed. Sleeping areas, on the rare occasions that they were found, usually indicated that animals had slept alone. However, a flattened area of leaves, consistent with the disturbance made at a sleeping site, was found a few meters from the corpse of a tapir found caught in a wire snare, suggesting that a second animal had slept there.

Tapirs are important seed dispersers (Bodmer, 1989). Williams (1980) found that Asian tapirs eat a variety of small fallen fruit, and we found that they also ate large fruits such as durian and jackfruit (Plate 2), and durian

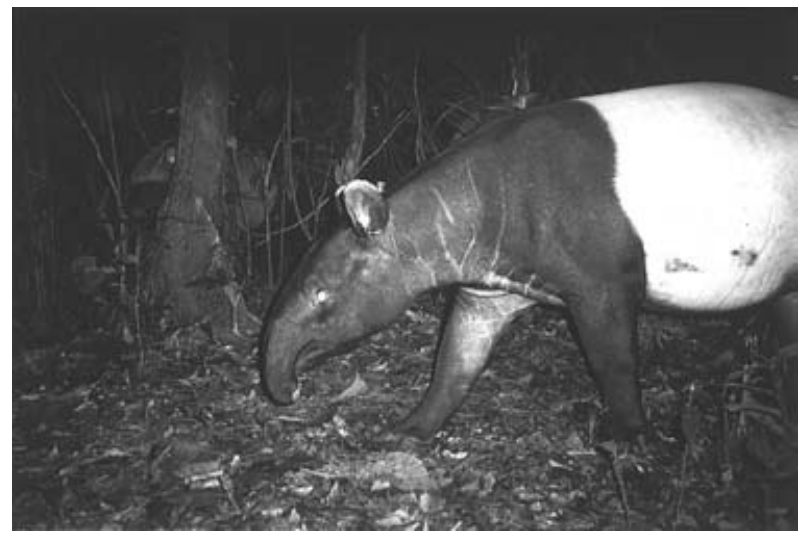

Plate 1 Tapirs were often photo-trapped moving in pairs, either two adults or a mother and calf. The two animals did not always follow the same path. In this photograph of two adults in Tandai one can just be seen moving through the forest beside the trail (Jeremy Holden).

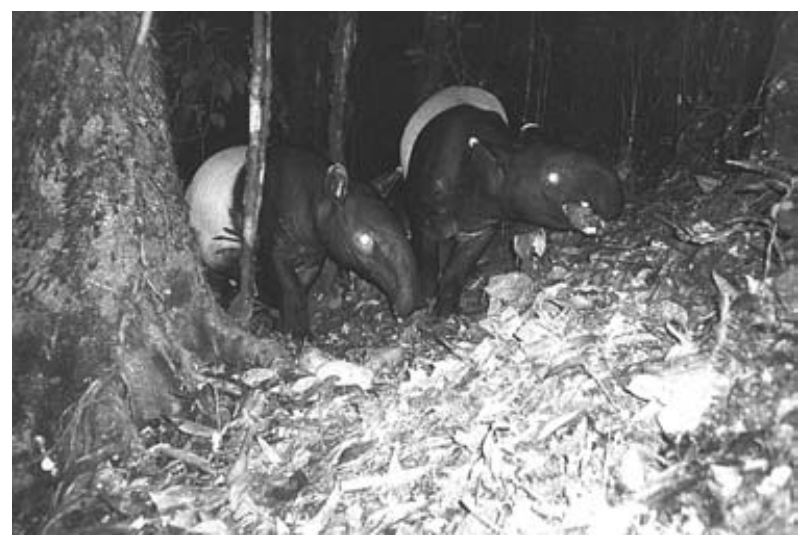

Plate 2 In Tapan tapirs were found to eat large fruits such as durian and jackfruit. In this photograph an adult female and large calf are eating jackfruit Artocarpus spp. (Jeremy Holden). seedlings were often observed sprouting from mounds of old tapir dung. In about $50 \%$ of instances dung piles were loosely buried by a scrap of humus. On Mount Tujuh where the colder climate meant that dung did not decay as quickly as in the hotter lowlands, it was observed that tapirs would sometimes defecate in the same spot, suggesting a territorial motive.

The $8 \mathrm{~km}^{2}$ study area in Tapan Valley was bisected by a road. No individual was photographed on both sides of the road (Fig. 3), indicating that it may have prevented tapirs crossing from one block of forest to another. However, as tapirs were rarely photographed at more than one camera placement (Fig. 3) movement between different forest blocks may be minimal. Phototrapping in this area coincided with a mass fruiting of durian and jackfruit. Active placements baited with durian made no photographs of tapirs, but those baited with jackfruit (9.7\% of placements) accounted for $40 \%$ of the total number of individuals photographed.

Premeditated hunting of tapirs by local people in KSNP was found to be rare. Tapirs are little known to even experienced forest hunters, and are often believed to be either a kind of pig or a hornless type of rhinoceros. The predominantly Muslim population considers its flesh to be haram (forbidden), and the species has no saleable parts. West Sumatran superstition also credits tapirs as an unlucky animal to kill, the consequences of which will cause crop failure. Nevertheless tapirs are caught in traps set for other species, either in the pit traps set for Sumatran rhinoceros (P. Wells, pers. comm.) or in wire snares set for tigers. The belief that they are a kind of pig means that on occasion they are considered legitimate prey by groups of pig hunters using dogs and hunting for sport. In some areas pig hunters call their dogs off if a tapir is flushed, believing the animal has a barbed tongue that can rasp the skin from a dog.

Tapir have reportedly been hunted when they have come into conflict with local people. In the Batang Asai area of Jambi traps were set for tapirs that were eating the bark of rubber trees, and in Taratak, West Sumatra, because they were eating watermelon and cucumber crops (Novarino, 2000). The Taratak trappers reportedly sold tapir meat to the Chinese community in nearby Padang, although as 'buffalo' (W. Novarino, pers. comm.). On Mount Tujuh a fisherman reportedly killed a tapir as it swam across a lake to escape an attacking tiger. The meat from this animal was smoked and sold as venison (an interesting coda to this story is that the people who bought and consumed the meat reportedly suffered stomach irritations.)

It seems that tapirs are not considered of any value for local traditional medicine. Reports were received of tapir bones being used in place of rhinoceros bones, but these are always sold as rhino products. One local 
medicine man sells oil made from shavings from the skull of a tapir - apparently as a relief from itching, but claims the skull is that of a rhinoceros (Plate 3).

Photographs showed that tigers will attack tapir. One tapir photographed carried scars consistent with a failed tiger attack: four clear puncture and dragged claw marks on its face. Whether tigers consistently prey on adult Asian tapirs is still open to speculation (Brooks \& Salas, 1997). However, of the $c .30$ tapirs photographed only one showed such scars (a male), compared with two muntjac Muntiacus muntjac from a total of $<20$ individuals. It is likely that tigers do sometimes take adult tapir, but such a formidable animal would probably be avoided where possible in favour of easier prey.

The most serious threat to the future survival of tapirs in Sumatra is the continued destruction of its forest habitat. This is reaching a crisis situation in Indonesia due to economic and political turmoil. It is symptomatic of these problems that two of the four study areas described in this report are no longer forested. The logged forests of Tandai were converted to oil-palm plantation, just as they were recovering, whilst the Tapan Valley has seen wholesale clearing by local people in the wake of illegal timber extraction and mining surveys. A return to this location in 1999 found that more than $50 \%$ of previous camera placement sites were no longer under forest cover. Although tapirs are using all types of forested habitat within the park, it is the lowland areas they seem to prefer that are most at risk (Holmes, 2001).

That tapirs are not seriously hunted for either meat or medicine bodes well for their continued survival. It is imperative that sufficient habitat is retained. To maintain the integrity of tapir habitat larger blocks of forest need to be targeted for special protection, lowland areas adjacent to the park that were excised for logging

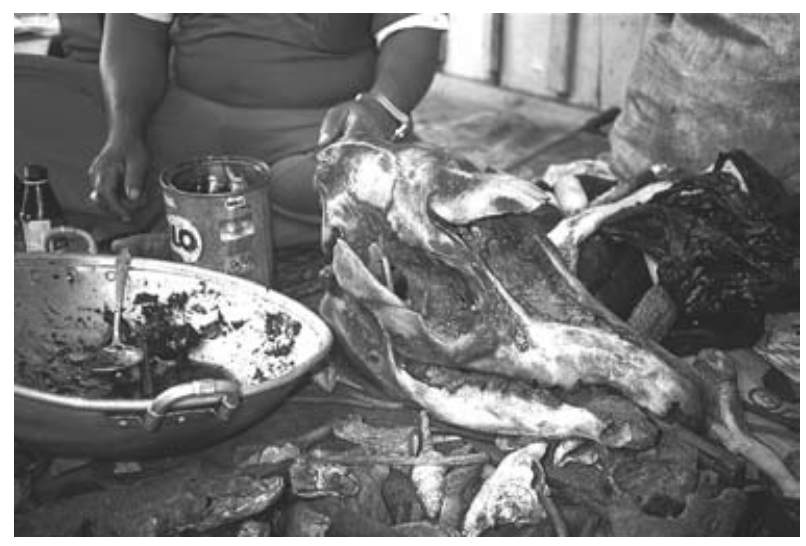

Plate 3 Asian tapir are not used in traditional medicine except when the bones are sold as those of Sumatran rhinoceros. This skull was seen in Sungai Penuh market (Jeremy Holden). concessions need to be reinstated into the protected area system, previously logged forest adjacent to KSNP must not be written off as having no conservation importance and therefore converted to plantations, and action needs to be taken to counter illegal logging and forest clearance.

The study site of Sipurak and its adjacent logging concession is a location where such initiatives could be implemented. This area has been identified as of crucial biodiversity importance, and controlling the fate of the adjacent logging concession is critical (Anon, 2001). This would provide a buffer to further encroachment, and increase the amount of protected lowland habitat. This type of initiative could be achieved in a number of ways: by repatriation of the whole, or part, of the concession back into KSNP, by discussion and agreement with the concessionaires to limit logging activities and road building close to the park boundaries, and by purchasing the rights to the concession and managing the area as a 'Conservation Concession' with controlled access and usage rights for local communities.

However, none of these recommendations are of any value unless they can be initiated under the umbrella of enforcement. Action has begun to try and curb poaching, illegal logging and encroachment, and Tiger Protection and Conservation Units are now patrolling KSNP, confiscating snare traps, chainsaws and illegal wood (Linkie et al., 2003). The impoverishment of the numbers of Sumatran rhinoceros through poaching and habitat loss has led some conservation scientists to regard KSNP as a lost cause. This is not, however, the case. For such an important regionally endemic species as the Asian tapir KSNP is an important protected area. The continued existence of a seemingly healthy population demonstrates that KSNP has a significant role to play in providing the habitat that this mammal requires for its survival.

\section{Acknowledgements}

We wish to thank the Indonesian Institute of Sciences for support and assistance with permits, and the Directorate General of Forest Protection and Nature Conservation for granting us permission to work in KSNP. We also thank Sahat Siregar and Harun Alrasyid from Component D (Monitoring and Evaluation) of the ongoing Integrated Conservation and Development Programme, Wilson Novarino for sharing his data from Taratak, Matt Linkie for constructing the maps, and the many tapir researchers throughout the world that answered our queries. Fieldwork was made possible by our many hard-working local field assistants and the inspiration of Korn. We thank members of the Tapir Preservation Fund for their invaluable support, especially 
Sheryl Todd. This report was written on a computer supplied by Heidi Forhring and the Tapir Preservation Fund. We are grateful to Dr Jito Sugardjito of the FFI Indonesia Programme, Matt Linkie, Dr Frank Lambert and Raleigh Blouch for commenting on drafts of the manuscript. Fauna \& Flora International financially supported the fieldwork.

\section{References}

Anon. (2001) Biodiversity Hotspots of the Kerinci-seblat Ecosystem: the Sipurak Hook, Kabupaten Merangin, Jambi. Justification for its Conservation and Options for Protection Strategy. KS-ICDP Component C1, Technical Report 1, Jaakko Pöyry, Jakarta, Indonesia.

Blouch, R.A. (1984) Current Status of the Sumatran Rhino and Other Large Mammals in Southern Sumatra. Unpublished Report, WWF, Bogor, Indonesia.

Bodmer, R.E. (1989) Frugivory in Amazonian artiodactyla: evidence for the evolution of the ruminant stomach. Journal of Zoology, 219, 457-467.

Brooks, D. \& Salas, L. (1997) Discussion on tapir as prey of big cats. Tapir Conservation, 7, 2-3.

Downer, C.C. (1996) The mountain tapir, endangered 'flagship' species of the high Andes. Oryx, 30, 45-58.

Fragoso, J.M. (1991) The effect of hunting on tapirs in Belize. In Neotropical Wildlife Use and Conservation (eds K.H. Redford \& J.G. Robinson), pp. 154-163. University of Chicago Press, Chicago, USA.

Gillison, A.N., Liswanti, N. \& Rachman, A. (1996) Rapid Ecological Assessment: Kerinci-seblat National Park Buffer Zone. Preliminary Report on Plant Ecology and Overview of Biodiversity Assessment. CIFOR Working Paper No. 14, Centre for International Forestry Research, Bogor, Indonesia.

Griffiths, M. (1993) Management of Large Mammals. Final Report, WWF (July 1991-April 1993), WWF-Indonesia.

Holden, J. (2002) Bird List of Kerinci Seblat National Park and Adjacent Areas. http://www.kerinci.org [accessed XX].

Holmes, D. (2001) Deforestation in Indonesia: A Review of the Situation in Sumatra, Kalimantan, and Sulawesi. World Bank, Jakarta, Indonesia.

IUCN (2002) 2002 IUCN Red List of Threatened Species. http:/ / www.redlist.org [accessed 12 December 2002].

Khan, M. (1997) Status and Action Plan of the Asian Tapir (Tapirus indicus). IUCN Gland, Switzerland.

Lekagul, B. \& McNeely, J.A. (1977) Mammals of Thailand. Association for the Conservation of Wildlife, Bangkok, Thailand.
Lynam, A.J. (1999) Camera-trapping reveals the status of Asian tapirs in southern Thailand rainforest remnants. Tapir Conservation, 9, 9-10.

Martyr, D. (1997) Important findings by FFI team in Kerinci Seblat, Sumatra, Indonesia Oryx, 31, 80-82.

Medici, E.P. \& Valdares-Pádua, C.B. (1999) Biologia da conservação da anta (Tapirus terrestris) e seu potencial como 'detetive ecológico' na região do Pontal do Paranapanema, São Paulo, Brasil. In Tapir Workshop, Proceedings of the IV International Conference on Wildife Management in Amazonia and Latin America, pp. 98-99. Fundación Moisés Bertoni and Florida University, Asuncion, Paraguay.

Medway, L. (1964) Post-Pleistocene changes in the mammalian fauna of Borneo. Studies Speleol, 1, 33-37.

Meijaard, E. (1998) The Asian tapir in Central Sumatra. Tapir Conservation, 8, 17.

Novarino, W. (2000) Conducting feeding and habitat studies in Sumatra. Tapir Conservation, 10, 6 .

O'Brien, T.G. \& Kinnaird, M.F. (1996) Birds and mammals of the Bukit Barisan Selatan National Park Sumatra, Indonesia, Oryx, 30, 207-217.

Salas, L.A. (1996) Habitat use by lowland tapirs (Tapirus terrestris L.) in the Tabaro River Valley, southern Venezuela. Canadian Journal of Zoology, 74, 1452-1458.

Santiapillai, C. \& Ramono, W.S. (1990) The status and conservation of Asian tapir in Sumatra, Indonesia. Tigerpaper, October-December, 6-11.

Williams, K.D. (1980) Browse use, feeding behaviour, and management of the Asian tapir. Journal of Wildife Management, 44, 489-494.

\section{Biographical sketches}

Jeremy Holden has worked as a photographer and field biologist in Indonesia, Viet Nam and Cambodia since 1995, and is a member of the Tapir Specialist Group.

Achmad Yanuar is a primatologist and a native of Sumatra. He has worked throughout the archipelago on various primate projects since 1995 .

Deborah J. Martyr has worked in KSNP since 1994, and is currently coordinating Tiger Protection \& Conservation Units in collaboration with the park management and the Indonesian Institute of Sciences. She is also a member of the Tapir Specialist Group. 